Cooper, P. D. (1957). J. gen. Microbiol. 17, 327-334

\title{
Some Characteristics of Vesicular Stomatitis Virus Growth-Curves in Tissue Culture
}

\begin{abstract}
By P. D. COOPER*
Divison of Biology, California Institute of Technology, Pasadena, California, U.S.A.

SUMMARY: Vesicular stomatitis virus was released exponentially and fairly reproducibly after infecting chick embryo cell monolayers. This system appeared suitable for chemical studies, which are to be presented separately; the present paper is concerned with growth-curve methods and a discussion of the system. When the average multiplicity of adsorption was 6 plaque-forming units/cell the latent period was 1-2 hr., and growth appeared to follow a one-step cycle. At least $62-75 \%$ of the cells were capable of releasing virus.
\end{abstract}

This paper is intended to show that vesicular stomatitis (VS) virus growing in chick embryo-cell monolayers is a suitable system for quantitative study. It describes the conditions used in such studies, the results of which are to be presented separately (Cooper, $1957 a, b$ ).

Intracellular chemical changes during infection should give information on virus growth, but a suitable system needs the following properties: $(a)$ virus should be assayed by particle count methods and should be released into a fluid medium and not extracted in unknown yield from whole tissue; $(b)$ onestep growth conditions must apply, so that changes take place in all cells together as much as possible (the most informative changes occur during the latent or exponential release periods which must be identifiable); $(c)$ nearly all cells must be infected at zero time, so that pathological changes are not masked by metabolism of healthy cells; $(d)$ samples must be representative and reproducible; $(e)$ cells should produce virus at an optimal rate, so that changes are maximal. These criteria are discussed below in relation to the system used. It is unfortunate that technical difficulties have hindered interpretation of many experiments with animal viruses (Bauer, 1952), because at least one of these properties was missing.

\section{METHODS}

General type of experiment. Most experiments involved harvesting one virus-infected and one control monolayer of embryo cells and the entire supernatant fluids after varying times during incubation at $37^{\circ}$. A group of monolayers all from the same batch were infected nearly simultaneously as described below, and a growth curve was obtained by plotting the total plaque-forming units (pfu) in the completely removed supernatant fluids against the time of harvesting. Thus six points on a growth curve would require six monolayers; successive samples from the same plate were not used. The method for harvesting the cells is given with the chemical methods (Cooper, 1957a).

* Present address: Virus Culture Laboratory, M.R.C. Laboratories, Carshalton, Surrey. 
Virus growth and phosphorus metabolism should be similar in cells prepared identically from chick embryos of the same age, and the state of any one monolayer and supernatant at a given time should represent that of all others from the same batch when treated identically. That these assumptions are justified is supported by: $(a)$ the reproducibility of the growth curves discussed below; $(b)$ the fairly smooth and reproducible nature of the ${ }^{32} \mathrm{P}$ uptake curves (Cooper, 1957 a) and the low standard deviations of the total ${ }^{32} \mathrm{P}$ taken up by two sets of 10 identical monolayers (about $5 \%$ of the mean uptakes).

Virus stocks. The virus used was a New Jersey (Missouri) strain of vesicular stomatitis virus kindly provided by Dr S. Madin, which had been shown to make good plaques on chick cells by Sellers (1955 and personal communication). All stocks were derived by diluted inoculum passage from a master culture, which was the $10 \mathrm{hr}$. supernatant fluid $(5 \mathrm{ml}$.) from a chick embryo monolayer infected with a suspension of a single well-separated plaque.

The presence of a transmissible interfering component ('incomplete virus'?) in some vesicular stomatitis virus stocks is to be reported elsewhere. All experiments described here and by Cooper $(1957 a, b)$ used stocks which are regarded as containing very little of this component, as they had high titres and were made by not more than three diluted passages from the original presumed single particle. Virus yields (pfu/cell) during experiments were high.

Stocks were kept at $-\mathbf{2 0} 0^{\circ}$ for not more than 3 months; the titre was generally $2 \times 10^{9} \mathrm{pfu} / \mathrm{ml}$., but some inactivation was detected on storage. Each cycle of freezing and thawing in Earle's saline $+4 \%(\mathrm{v} / \mathrm{v})$ serum resulted in an inactivation of about $15 \%$ of the plaque-forming units.

Virus assay. The plaque method used was that described by Rubin, Baluda \& Hotchin (1955) for Western Equine Encephalomyelitis virus and cells from 10-day chick embryos, except that embryo extract in the agar overlay was replaced by $5 \mathrm{mg} . / \mathrm{ml}$. lactalbumin hydrolysate $+1 \mathrm{mg}$. $/ \mathrm{ml}$. yeast extract + $1 \mathrm{mg}$. $/ \mathrm{ml}$. crystalline bovine plasma albumin (Dr J. S. Youngner, personal communication). The curves presented are relative assays not corrected for plating efficiency, and amounts of virus are described in terms of plaqueforming units in the assay system used. Growth and storage took place entirely in darkness, and during virus assays virus was in serum-free media for less than $5 \mathrm{~min}$. under exclusively artificial (fluorescent strip) lighting, so that light inactivation (Skinner \& Bradish, 1954) was negligible. One plaque results from a single 'infective centre' (Franklin, personal communication); the 'infective centre' may be a clump of virus particles but virus preparations gave single-hit X-ray and UV inactivation curves and were therefore presumed to be monodisperse, so that one plaque results from one infective virus particle. The average multiplicity of infection was determined from the number of pfu adsorbed by the monolayer and the number of cells present in the monolayer. The number of cells was found by haemocytometer counts of a trypsin re-suspension. The number of pfu adsorbed to individual cells was assumed to follow a Poisson distribution. Whether all the particles adsorbed to a cell or only a fraction thereof participate in viral reproduction within that cell is at present unknown. 
Media. Earle's saline (1943) containing $4 \%(\mathrm{v} / \mathrm{v})$ horse or more often ox serum $(\mathrm{ES} / \mathrm{Ox})$ was added to infected or control monolayers for the period of virus release; no difference was found between sera provided that antiviral activity was absent. Serum was included for its small stimulation of the rate of ${ }^{32} \mathrm{P}$ uptake and better effect on appearance of cells, particularly after $20 \mathrm{hr}$. Virus was diluted for assay in phosphate buffer saline (PBS, Dulbecco \& Vogt, 1954a).

Preparation of monolayers of chick embryo cells. Monolayers were prepared for growth-curves and for routine plaque-assays by the same method. This was either the pulping procedure described by Rubin et al. (1955), or else the embryos were coarsely minced and digested by gentle agitation in trypsin (Melnick, 1955). The latter method gives three to four times as many cells as the former and the performance of the monolayers appears to be identical. Monolayers were always used for growth-curves (and usually for assays) after $20 \mathrm{hr}$. incubation when cells had spread to form a continuous sheet. The ${ }^{32} \mathrm{P}$ uptake continued at a constant rate for the first $\mathbf{2}$ days but had nearly ceased by the third day.

Method employed for one-step growth-curves. To infect the cells, medium was removed from $20 \mathrm{hr}$.-monolayers which were then washed once (or three times when containing ${ }^{32} \mathrm{P}$ ) with $5 \mathrm{ml}$. ES/Ox. After washing, $0.5 \mathrm{ml}$. of ES/Ox containing virus at known titre (or without virus for controls) was added, and allowed to spread over the whole surface $(2-3 \mathrm{~min}$.), when the plates were incubated at $37^{\circ}$ in a humid atmosphere containing approximately $5 \% \mathrm{CO}_{2}$ for $30 \mathrm{~min}$. Addition of $4.5 \mathrm{ml}$. of warm ES/Ox was followed by washing in some experiments, but where washing is not mentioned the medium was allowed to remain on the plates at $37^{\circ}$ until entirely removed at different times and frozen pending virus assay. Unless otherwise mentioned, the inoculum contained $7.5 \mathrm{pfu}$ for each cell in the monolayer, and assay of the medium shortly after making up to $5 \mathrm{ml}$. showed that adsorption was $60-90 \%$ complete (average $80 \%$ ) giving a final average multiplicity of adsorption of 5-6. Little further VS virus was adsorbed by $10 \mathrm{~cm}$. Petri dish monolayers after $30 \mathrm{~min}$. with $0.5 \mathrm{ml}$. of inoculum, and an average multiplicity of 1 was probably reached $10-15 \mathrm{~min}$. after its addition. The time of first addition of virus was regarded as zero, so that the latent periods include the period required for the virus to come into contact with the cells.

\section{RESULTS}

Establishment of the time required for a presumed one-step growth-curve

Fig. 1 shows the virus release-time relationships obtained from a number of experiments using the growth-curve method described above. Duplicates agreed well, and fairly smooth curves were obtained. The latent period is defined throughout the present work as the average time required for each cell to release one pfu; this is regarded as the least ambiguous way of defining the rate of development of a system in which no sharply delineated 'burst' occurs. The latent period is determined when necessary by extrapolating the 


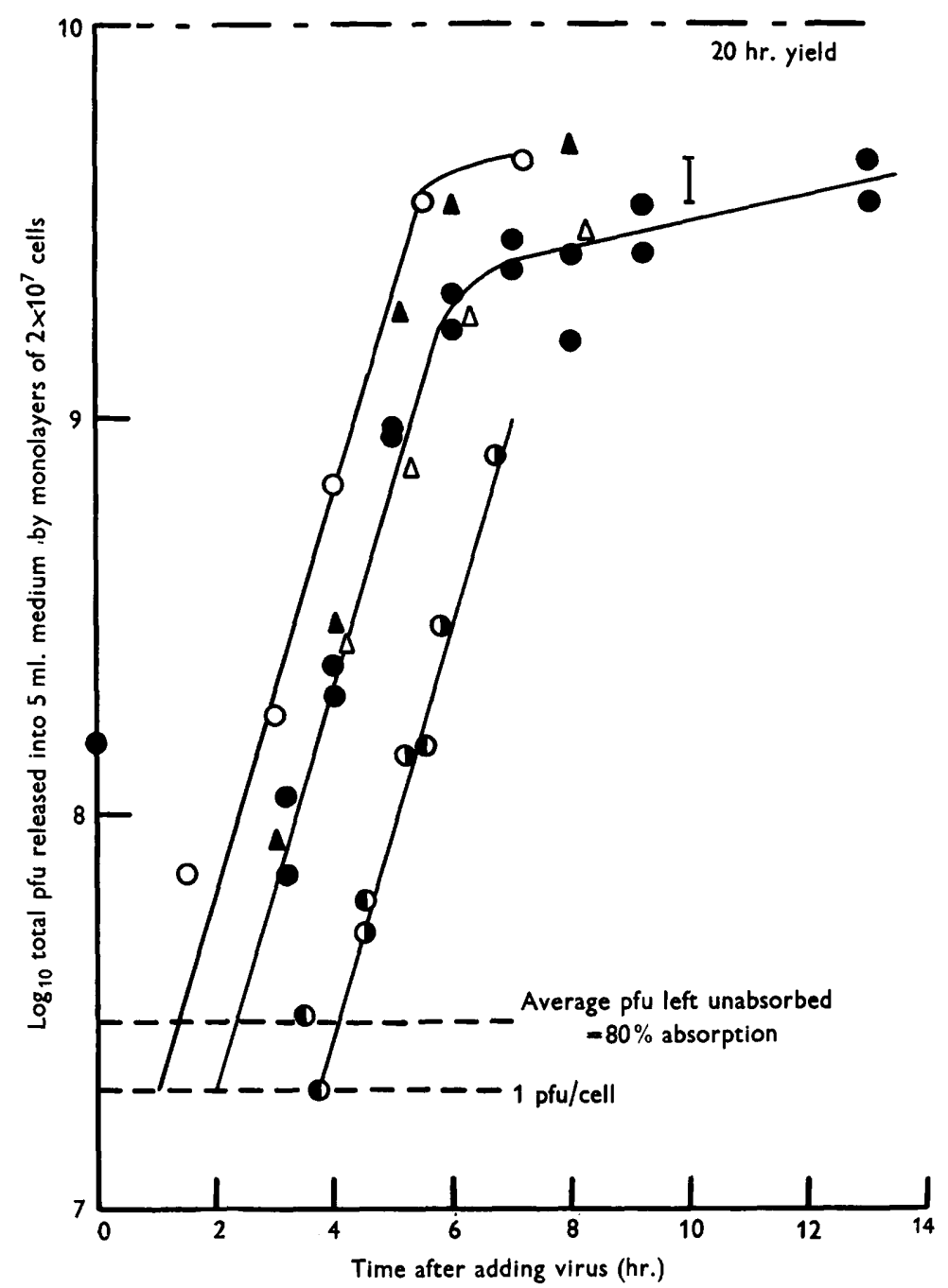

Fig. 1. Total number of plaque-forming units released by chick embryo cell monolayers $\left(2 \times 10^{7}\right.$ cells $)$ infected to an average multiplicity of adsorption of 6 with vesicular stomatitis virus. All points of each curve were obtained with the same batch of plates, but except where mentioned the complete curves were made on separate occasions with different batches of plates. Two experiments $(\mathrm{O}-\mathrm{O}$, washed once; $-\mathrm{O}$, washed three times) are given to show the extreme range in latent period encountered among twelve experiments; in all the experiments virus release increased exponentially at similar rates. Variations between duplicates are shown by $(-)$; $(\Delta-\Delta)$ was washed once and $(\Delta-\Delta)$ was washed three times with medium before infection, but were otherwise identical and from the same batch of plates. Two curves $(--0)$ and (D-D) were infected with multiplicity 1-2 (uncorrected for cells theoretically uninfected) but otherwise were identical with those of multiplicity $=6$. The bar at $10 \mathrm{hr}$. indicates the range of the yields from seven different multiplicities of adsorption varying from 0.5 to 23 . The point on the ordinate represents the virus added as inoculum for multiplicity $=6$, and the middle broken horizontal line the average amount of virus left unadsorbed after $30 \mathrm{~min}$; the lowest broken line indicates the level of termination of the latent period, and the uppermost broken line the average $20 \mathrm{hr}$. yield from once-washed monolayers. 
exponential rise in a logarithmic plot back to 1 pfu/cell. The average latent period was $1.5 \mathrm{hr}$. at a multiplicity of 6 ; all latent periods at this multiplicity fell within the range of $1 \cdot 0-2 \cdot 0 \mathrm{hr}$. Exponential release of $50 \%$ of the final yield occurred up to $6 \mathrm{hr}$., and the remainder was released more slowly for some hours further. Although the latent periods varied somewhat between experiments, the rates of virus release were closely similar, and except as described the final yields were also similar; the threefold washing of the plates before infection required by some experiments gave a considerably lower yield than one wash. The small differences in latent period may be due to factors (such as small variations between batches of plates) other than differences in washing of the plates, as one experiment with the same batch of plates where the washings differed gave similar latent periods although slightly different rates of release and different final yield.

\section{Proportion of cells supporting viral growth}

Adsorption of $12 \times 10^{7}$ pfu by a uniform confluent monolayer of $2 \times 10^{7}$ cells should be sufficient to place virus on $99 \cdot 7 \%$ of the cells. That most cells with adsorbed virus are capable of supporting growth is regarded as proved by the following observations: (a) $40 \mathrm{hr}$. plaques on chick embryo monolayers show a fairly sharp boundary within which no live cells are visible, so that none of the population is completely resistant; $(b)$ as described elsewhere (Cooper, 1955), when cells were removed during the latent period with $\mathbf{0 \cdot 2 5} \%$ trypsin from monolayers infected to multiplicity of 6-7, 62-75\% of the cells counted in a haemocytometer were able to produce plaques when mixed in an agar cell suspension containing $2 \times 10^{7}$ non-infected cells $/ \mathrm{ml}$. All cells visible were included in the count, even those apparently in poor condition, so that the considerable chance of cell trauma during their treatment means that this figure of $62-75 \%$ is certainly appreciably low. Evidence was presented by Dulbecco \& Vogt (1954a) to show that cells in a monkey kidney monolayer were equally susceptible to poliovirus.

\section{Effect of multiplicity of adsorption}

Fig. 1 shows that the two release curves with multiplicity $\mathbf{1}$ to $\mathbf{2}$ had a longer latent period than those with multiplicity 6 , while the rate of release and $10 \mathrm{hr}$. yield were independent of multiplicity. These effects will be discussed more extensively elsewhere. Meanwhile the presentation of these experiments is anticipated in Fig. 2, as the effect of multiplicity of adsorption on latent period has some important inferences for chemical studies.

As cells probably adsorb virus according to a Poisson distribution, the multiplicity of individual cells in an infected monolayer will vary. The effect of multiplicity of adsorption on latent period will mean therefore that at any one time the cells in such a monolayer will be at different stages of their growth cycle. This is a characteristic undesirable for chemical study but one which appears inevitable if one insists that all cells are infected initially. To estimate the extent of the discrepancies, theoretical release curves were constructed for an ideal monolayer randomly infected to an average multiplicity of 6 by 
applying the observed relationships between multiplicity and latent period, and assuming that cells at different multiplicities release virus at the same exponential rate and to the same yield, even though starting at different times. It is further assumed that all cells of the same multiplicity start together, and

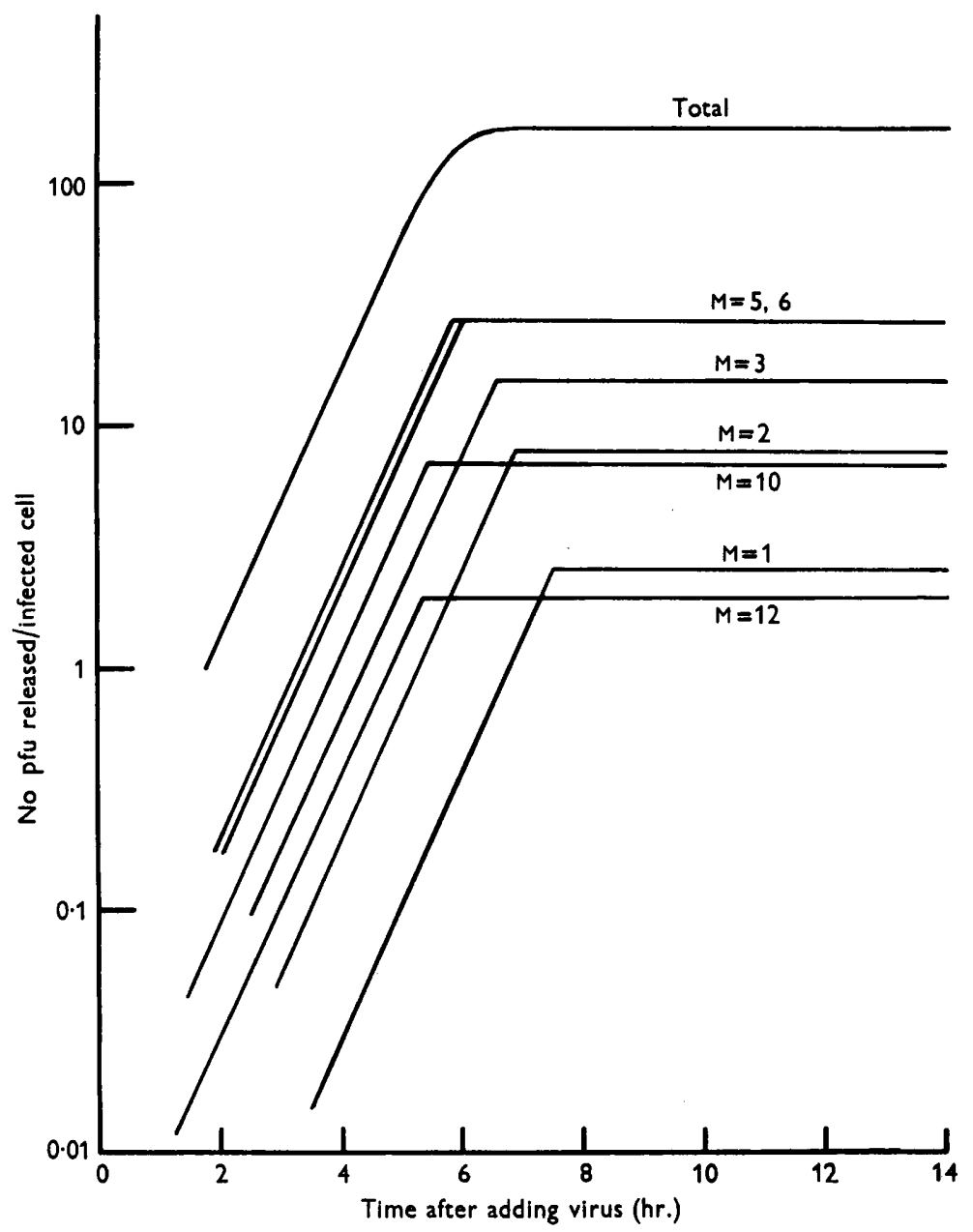

Fig. 2. Theoretical curves attempting to evaluate the differences in virus release to be expected from a Poisson distribution of multiplicity of infection in a monolayer infected to an average multiplicity of 6 (multiplicities higher than 12 are ignored). The commencement of each curve corresponds with release of one pfu for the average cell at that multiplicity, and is calculated from the latent periods of monolayers infected to that multiplicity as an average; only seven of the twelve curves are given.

the later non-exponential release is ignored. Some illustrative curves are given in Fig. 2. From these curves it can be calculated that $80 \%$ of the cells are less than $0.7 \mathrm{hr}$. apart in starting or completing their release, $60 \%<0.4 \mathrm{hr}$. apart and $30 \%<0 \cdot 1 \mathrm{hr}$. apart; a negligible proportion of cells complete their release more than $0 \cdot 6 \mathrm{hr}$. before the mean time for completion. As samples are 
usually taken $1 \mathrm{hr}$. apart this probably means that virus growth will be sufficiently synchronized for any chemical change due to virus growth to be the major one, and not to be too obscured by healthy metabolism of latestarting cells or lysis of early starters. Nevertheless, the fact that these curves represent only an average would have to be borne in mind in, for example, placing any small change in its correct time sequence with regard to virus growth. The theoretical curves do not, of course, consider cells which are early or late starters for reasons other than multiplicity, and some further spread will be introduced by the non-simultaneous infection of the cells due to the $30 \mathrm{~min}$. adsorption period required.

\section{DISCUSSION}

That the experiments described above represent one-step growth cycles is demonstrated by: $(a)$ relatively rapid adsorption of sufficient plaque-forming units to infect all cells initially; $(b)$ release of virus by most infected cells; (c) the release of $50 \%$ of virus within the exponential period, without previous or subsequent steps; $(d)$ the similarity of other animal virus growth systems likely to be one-step curves (Dulbecco, 1955); $(e)$ the almost simultaneous cessation of ${ }^{32} \mathrm{P}$ uptake by many fractions without concurrent lysis during the exponential period (Cooper, 1957a), indicating that most cells are affected at this time.

Continued slow non-exponential release may be a function of delayed cell death, as by $6 \mathrm{hr}$. less than $25 \%$ of the cells were 'rounded-up' and release of phosphorus from most cellular fractions was very small (Cooper, 1957a). Thus non-specific lysis at this stage must also be small. Most cells were rounded and lysis was extensive by $20 \mathrm{hr}$.

It is a disadvantage of this system that the cell population is not homogeneous and can be seen to contain fibroblast and epithelial type cells. However, fibroblasts are in considerable excess, and a mixture probably does not matter for the present purpose, as McClain \& Hackett (1955) showed that latent and release periods of VS virus were closely similar in three epithelial and two fibroblast cultures from five different vertebrate species; of these systems chick cells produced most virus and therefore may show most changes. The intact monolayer was preferred for virus growth to the cell suspension method for this reason, as the latter often gave lower yields per cell (see also Dulbecco \& Vogt, 1954b).

It thus appears that most of the criteria listed in the introduction as necessary for chemical studies are fulfilled by this system.

I am very grateful to my colleagues at the California Institute for stimulating discussions; in particular to Dr R. Dulbecco and Dr G. W. Beadle, and to the Gosney Fund Board of Trustees, the American Cancer Society Inc., and the American Cancer Society, California Division, for financial support as a Research Fellow. I am indebted to the Wright-Fleming Institute of Microbiology, St Mary's Hospital, London, for leave of absence. 


\section{REFERENCES}

BAUER, D. J. (1952). Metabolic aspects of virus multiplication. In 'The nature of virus multiplication'. Symp. Soc. gen. Microbiol. 2, 46.

Cooper, P. D. (1955). A method for producing plaques in agar suspensions of animal cells. Virology, 1, 397.

Cooper, P. D. (1957a). Paths of phosphate transfer in normal chick embryo cells and in cells infected with vesicular stomatitis virus. J. gen. Microbiol. 17, 335.

Cooper, P. D. (1957b). An osmotic barrier for inorganic phosphate in chick embryo cells and its stability during the latent and release periods of infection by vesicular stomatitis virus. J. gen. Microbiol. 17, 353.

Dulbecco, R. (1955). Interaction of viruses and animal cells. A study of facts and interpretations. Physiol. Rev. 35, 301.

Dulbecco, R. \& Vogt, M. (1954a). Plaque formation and isolation of pure lines with poliomyelitis viruses. J. exp. Med. 99, 167.

Dulbecco, R. \& Vogt, M. (1954b). One-step growth curves of western equine encephalomyelitis virus on chicken embryo cells grown in vitro and analysis of virus yields from single cells. J. exp. Med. 99, 183.

Earle, W. R. (1943). Production of malignancy in vitro. IV. Mouse fibroblast cultures and changes seen in living cells. J. nat. Cancer Inst. 4, 165.

MCClıAIN, M. E. \& HACKETT, A. J. (1955). Comparison of growth of vesicular stomatitis virus in five tissue culture systems. Fed. Proc. 14, 471.

Melnick, J. C. (1955). Tissue culture techniques and their application to original isolation, growth and assay of poliomyelitis and orphan viruses. Ann. N.Y. Acad. Sci. 61, 754.

Rubin, H., Baluda, M. \& Hotchin, J. E. (1955). The maturation of western equine encephalomyelitis virus and its release from chick embryo cells in suspension. J. exp. Med. 101, 205.

SELLERs, R. F. (1955). Growth and titration of the viruses of foot-and-mouth disease and vesicular stomatitis in kidney monolayer tissue cultures. Nature, Lond. 176, 547.

Skinner, H. H. \& Bradish, C. J. (1954). Exposure to light as a source of error in the estimation of the infectivity of virus suspensions. J. gen. Microbiol. 10, 377 . 